\title{
HISTOGENESIS OF HUMAN FETAL RENAL MEDULLA
}

Rahul Kisan Ukey ${ }^{1}$, Reshma Baburao Shinde ${ }^{* 2}$, Anil Shivshankar Rahule ${ }^{3}$, A Prafulla Nikam ${ }^{4}$, C.V. Diwan ${ }^{5}$.

${ }^{1}$ Assistant Professor, Department of Anatomy, GMC, Rajnandgaon, C.G., India.

${ }^{* 2}$ Assistant Professor, Department of Anatomy, B.J. Medical College, Pune, Maharashtra, India.

${ }^{3}$ Professor, Department of Anatomy, GMC, Rajnandgaon, C.G., India.

${ }^{4}$ Associate Professor, Department of Anatomy, GMC, Rajnandgaon, C.G., India.

${ }^{5}$ Ex-Head and Professor, Department of Anatomy, GMC, Aurangabad, Maharashtra, India.

\section{ABSTRACT}

Introduction: Histogenesis of kidney gives knowledge regarding histological maturity of kidney and its functional status at the given gestational age. Kidney is developed from two parts, metanephrogenic blastema and ureteric bud. Metanephrogenic blastema gives origin to secretory part i.e. nephron while ureteric bud forms the collecting part i.e. collecting tubules and ureter. Both these parts fuse with each other and the development becomes complete.

Materials and Methods: 50 aborted human fetuses between 13-36 weeks of gestational age were used for this study with no obvious congenital anomalies. The 2-3 mm thick cut sections of both kidneys were taken, processed and Paraffin blocks were prepared. 5-7 micron thick sections were taken with rotary microtome, mounted and then stained with Haematoxylin and Eosin. Microscopic features were observed in low and high power and then documented.

Results and Discussion: Differentiation between cortex and medulla was seen from 16-18 week onwards. The medulla with collecting ducts, thick and thin segment of loop of Henle became well differentiated from 16 week onwards. Vascularity of medulla increased with increase in gestational age while connective tissue decreased with increase in gestational age. Renal pelvis was lined by transitional epithelium.

KEY WORDS: Histogenesis, Renal Medulla, Gestational age, Collecting ducts, Loop of Henle, Transitional epithelium.

Address for Correspondence: Dr Reshma Baburao Shinde, Assistant Professor, Department Of Anatomy, B.J. Medical College, Pune, Maharashtra, India. E-Mail: sreshma10@gmail.com

\begin{tabular}{|c|c|c|c|}
\hline Access this Article online & \multicolumn{3}{|c|}{ Journal Information } \\
\hline \multirow[t]{4}{*}{ Quick Response code } & \multicolumn{3}{|c|}{ International Journal of Anatomy and Research } \\
\hline & \multicolumn{2}{|c|}{$\begin{array}{cc}\text { ICV for 2016 } \\
90.30\end{array} \begin{array}{c}\text { ISSN (E) 2321-4287 | ISSN (P) 2321-8967 } \\
\text { https://www.ijmhr.org/ijar.htm } \\
\text { Dol-Prefix: https://dx.doi.org/10.16965/ijar }\end{array}$} & \\
\hline & \multicolumn{3}{|c|}{ Article Information } \\
\hline & \multirow{2}{*}{$\begin{array}{l}\text { Received: } 07 \text { Jun } 2018 \\
\text { Peer Review: } 07 \text { Jun } 2018 \\
\text { Revised: None }\end{array}$} & \multicolumn{2}{|c|}{$\begin{array}{l}\text { Accepted: } 02 \text { Jul } 2018 \\
\text { Published (O): } 10 \text { Aug } 2018\end{array}$} \\
\hline DOI: 10.16965/ijar.2018.277 & & \multicolumn{2}{|c|}{ Published (P): 10 Aug 2018} \\
\hline
\end{tabular}

\section{INTRODUCTION}

The development of fetus begins with the formation of zygote and it goes on dividing to form various germ layers from which all the organ system gets developed. One should know the normal developmental gross and microscopic anatomy for better understanding of various congenital renal conditions. The various text books [1-4] of embryology does not describe the details of microscopic appearance of various structures of medulla of kidney and their maturation at different gestational ages. So microscopic development of medulla of kidney is still unclear to us. In this regard, this study gives information about histological development of medulla of human kidney and the time sequence in which it develops. This study can also be used for determination of gestational 
age of fetus for medico-legal purpose.

The internal macrostructure of the kidney is divided into outer cortex and inner medulla. The renal medulla consists of pale, conical renal pyramids, their bases directed to the cortex and apices converging to the renal sinus. At the renal sinus they project into calyces as papillae. One minor calyx receives 1 to 3 renal papillae [5].

Metanephros, the primordia of permanent kidneys, appear in lumbosacral segments and start to develop early in 5th week and begin to function approximately after 4 weeks [2].

Since the beginning of 19th century, research has been done on structural development of kidney. According to Helena Maria et al [6] nephrogenesis in human begins at 6 th week of intrauterine life and completed by 35th week of gestation. After 25 weeks, cortico-medullary differentiation becomes more distinct. Mishra $S$ et al [7] stated that, at 16 weeks of gestation, the medulla showed mesenchymatous tissue with some developing tubules. At 22 weeks, medulla appeared to be more mature. Tank KC et al [8] observed that, with increase in gestational age, medulla showed well differentiated collecting tubules, thick and thin segments of loop of Henle.

\section{MATERIALS AND METHODS}

The present study was carried out in the department of Anatomy, Government Medical College, Aurangabad, Maharashtra, India. This study was done on 50 aborted fresh human fetuses (29 females and 21 males) between 13-36 weeks of gestational age with no obvious congenital anomalies. These fetuses were obtained from the Department of Obstetrics and Gynaecology of the same institute with the prior permission of Head of the Department and consents of respective parents. The study was approved by the institutional Ethical Committee. These fetuses included the spontaneous abortuses, stillborns and terminated fetuses under the Medical Termination of Pregnancy Act of India.

$10 \%$ formalin was injected in thoracic and abdominal cavity to fix the fetuses. The fetuses were then kept in $10 \%$ formalin jar and then dissected within 2 hours of collection. Anterior abdominal wall was cut by taking midline vertical incision, abdominal cavity opened and both kidneys were removed. 2-3 mm thick longitudinal sections of both right and left kidneys were taken, passing through cortex, medulla and hilum. Specimens were kept in Bouin's fluid for 4-5 days. The blocks were labeled and prepared for cutting. 5-7 micron thick sections were taken with the help of a rotary microtome. Sections were then stained by the Haematoxylin and Eosin. Histogenesis of the kidney was studied by examining the slides under low and high power of light microscope.

\section{OBSERVATIONS AND RESULTS}

The findings of the present study at various gestational ages were as follows:

At 13 weeks: The medulla consisted of undifferentiated mesenchymal tissue containing spindle shaped cells with oval nuclei and pale cytoplasm. Within the mesenchymal tissue, irregular tubules of various dimensions were seen. Some tubules were found to be lined by columnar cells with clear cytoplasm and vesicular nuclei. These were probably the collecting tubules. Few tubules of smaller dimension, lined by simple cuboidal cells with eosinophilic cytoplasm and rounded nuclei were seen, probably thick segments of the loop of Henle. Some tubules lined by squamous epithelium and having small lumen were seen, representing the thin segments of loop of Henle. Blood vessels lined by simple squamous epithelium, with RBCs were seen (photomicrograph 1).

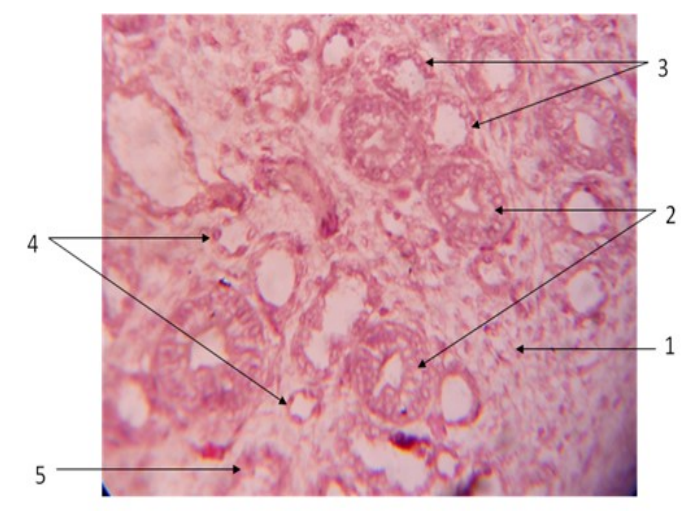

Photomicrograph 1: Kidney (medulla); LS; 13weeks; H\&E; 40X

(1. Mesenchymal tissue, 2. Collecting tubule, 3. Thick segment of loop of Henle, 4. Thin segment of loop of Henle, 5. Blood capillary)

At 16 weeks: Differentiation between cortex and medulla was seen (photomicrograph 2). The amount of mesenchymal connective tissue was reduced than the previous stage. The collecting tubules possessed larger diameter and were 
lined by columnar cells while the thick segments of loop of Henle were lined by cuboidal epithelium. The thin segments of loop of Henle were lined by squamous epithelium and had small lumen. Increased number of collecting tubules, thick and thin segments of loop of Henle were seen as compared to the previous stage (photomicrograph 3).

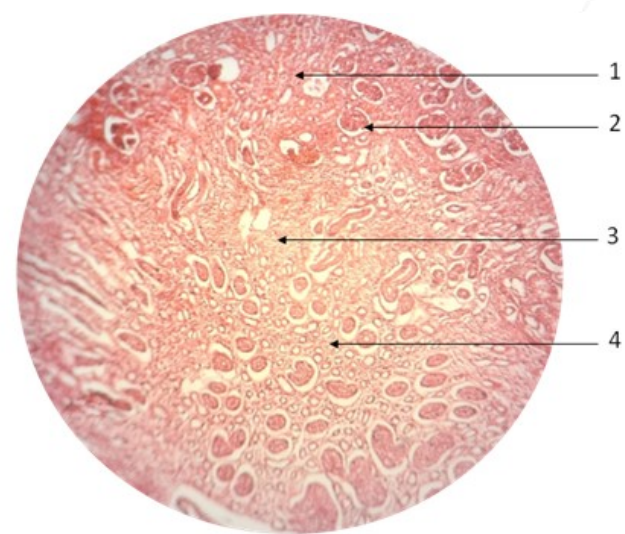

Photomicrograph 2: Kidney (cortico-medullary junction); LS; 16 weeks; H\&E; $40 X$

(1. Juxta medullary cortex, 2. Developing renal corpuscle, 3. Cortico-medullary Junction, 4. Medulla)

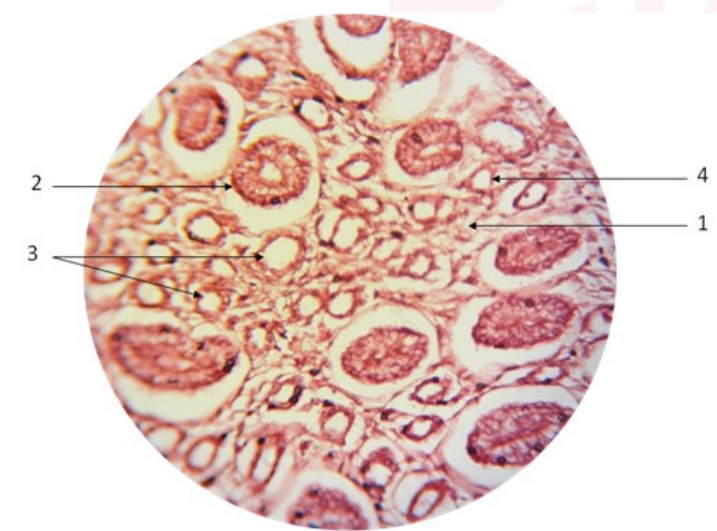

Photomicrograph Kidney 3: (medulla); LS; 16 weeks; H\&E; 40X (1. Mesenchymal tissue, 2. Collecting tubule, 3. Thick segment of loop of Henle, 4. Thin segment of loop of Henle )

The renal pelvis lined by transitional epithelium was seen at the hilum of kidney. The papillary duct opening into the minor calyx was also observed (photomicrograph 4).

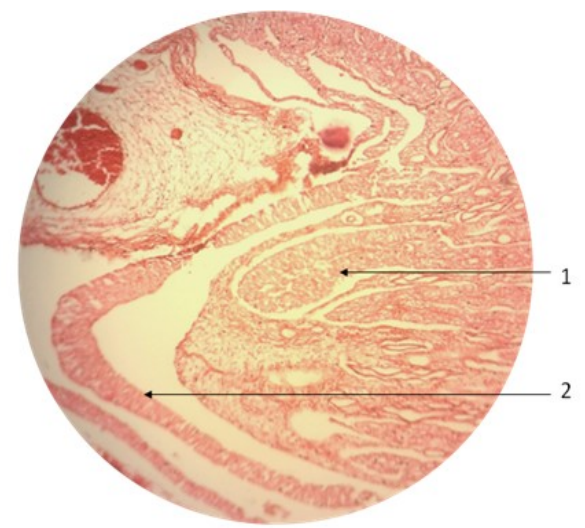

Photomicrograph 4: Kidney (pelvis); LS; 16 weeks; H\&E; 10X (1. Papillary duct, 2. Transitional epithelium)
At 20 weeks: The mesenchymal tissue was found to be reduced in amount while the developing tubules increased in number than the previous stage. The collecting tubules, thick and thin segments of loop of Henle were better differentiated than the previous stage. Vascularity of the kidney was increased compared to the previous stage as indicated by more RBCs within the capillaries. (photomicrograph 5).

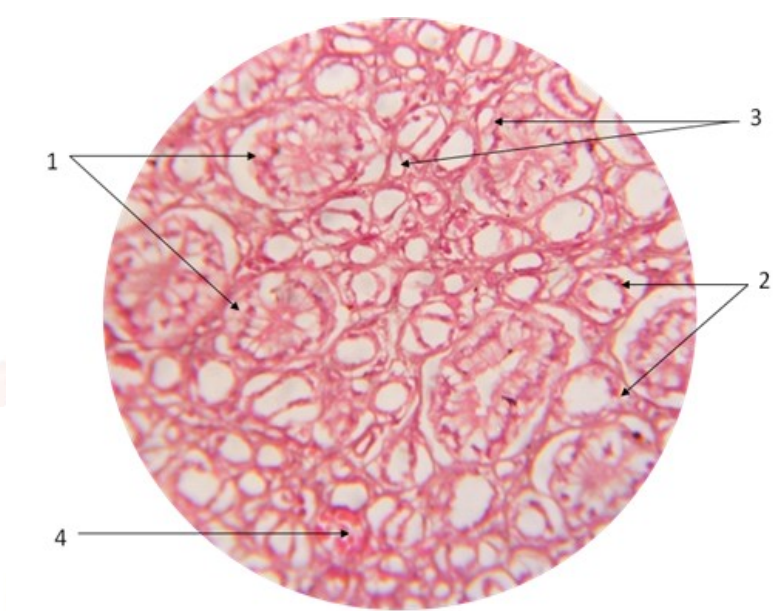

Photomicrograph 5: Kidney (medulla); LS; 20 weeks;H\&E; 40X (1. Collecting duct, 2. Thick segment of loop of Henle, 3. Thin segment of loop of Henle, 4. Blood capillary)

At 24 weeks: The collecting tubules, thick and thin segments of loop of Henle were distinctly identified and their number increased. The connective tissue was reduced in amount than the previous stage. Blood capillaries containing RBCs were increased in number (photomicrograph 6).

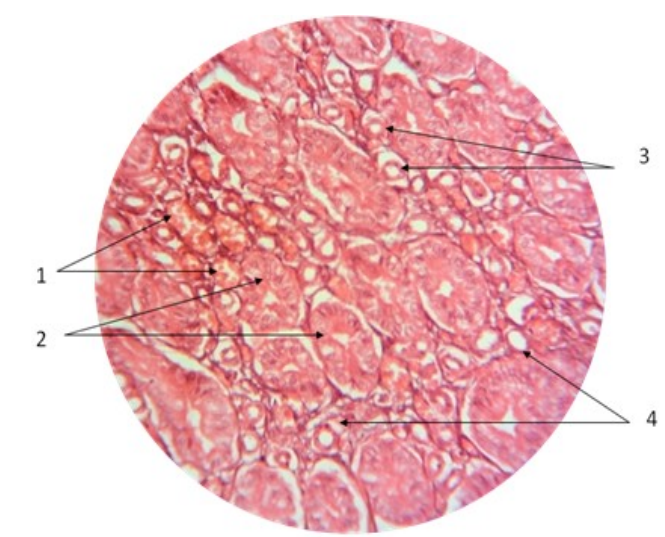

Photomicrograph 6: Kidney (medulla); LS; 24 weeks; H\&E; 40X

(1. Blood cpillaries, 2. Collecting duct, 3 . Thick segment of loop of Henle, 4. Thin segment of loop of Henle)

At 32 weeks: Medulla of kidney appeared more mature. Amount of connective tissue decreased in amount, the number of collecting tubules, thick and thin segments of loop of Henle were 
increased than the previous stage (photomicrograph 7).

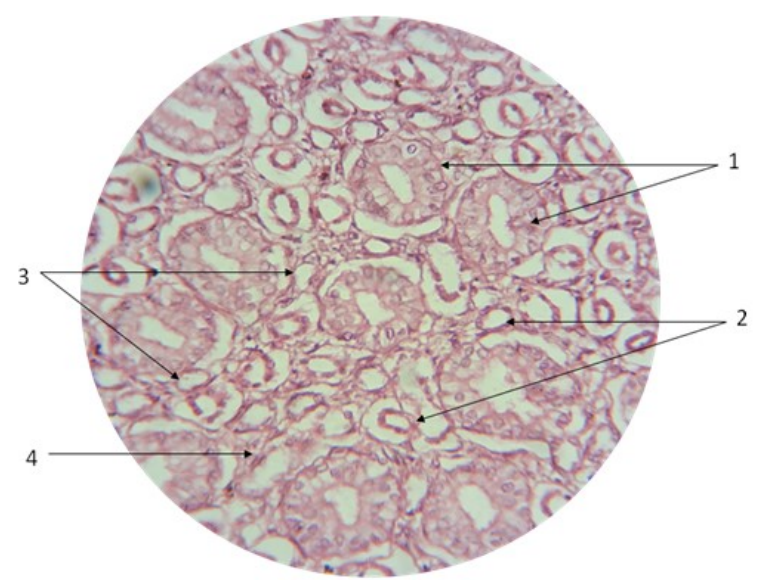

Photomicrograph 7: Kidney (medulla); LS; 32 weeks; H\&E; 40X

(1. Collecting duct, 2. Thick segment of loop of Henle,

3. Thin segment of loop of Henle, 4. Mesenchymal tissue )

At 36 weeks: Cortico-medullary junction was clearly demarcated (photomicrograph 8). The medulla showed well differentiated collecting tubules, thick and thin segments of loop of Henle (photomicrograph 9).

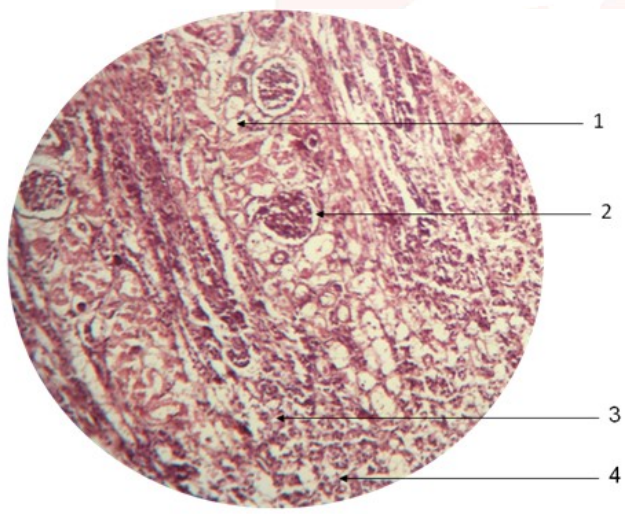

Photomicrograph 8: Kidney (cortico-medullary junction); LS; 36 weeks; H\&E; $10 X$

(1. Juxta-medullary cortex, 2 . Juxta-medullary renal corpuscle, 3. Cortico-medullary Junction, 4. Medulla)

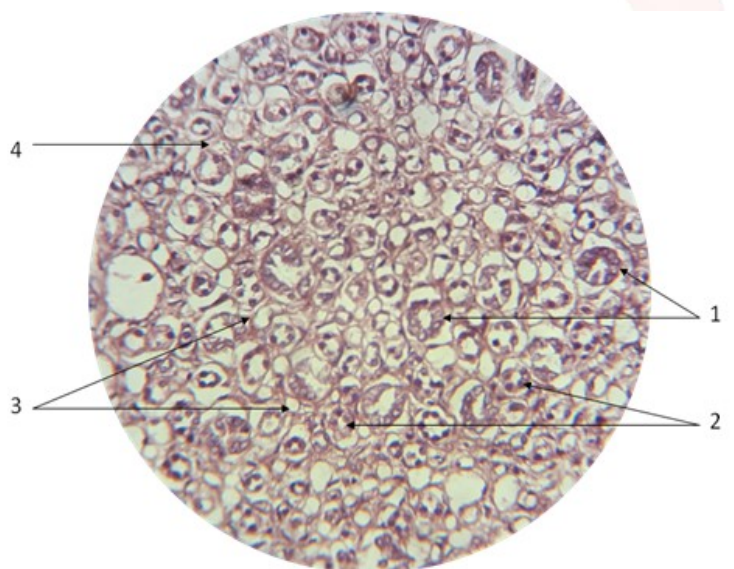

Photomicrograph 9: Kidney (medulla); LS; 36 weeks; H\&E; 40X (1. Collecting duct, 2. Thick segment of loop of Henle,

3. Thin segment of loop of Henle, 4. Blood capillary)

Renal pelvis was seen, lined by transitional epithelium (photomicrograph 10).

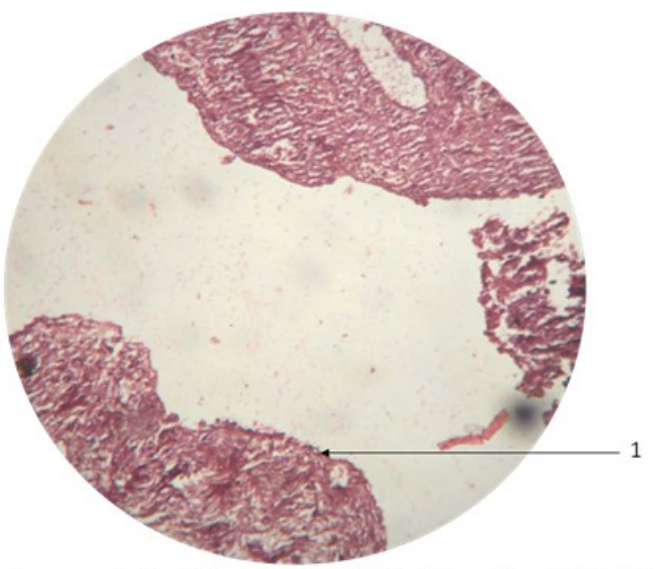

Photomicrograph 10: Kidney (pelvis); LS; 36 weeks; H\&E; 40X (1. Transitional epithelium)

\section{DISCUSSION}

In the present study, at $13^{\text {th }}$ week of gestation, within the mesenchymal tissue, irregular tubules of various dimensions were seen. Some tubules were lined by columnar cells with clear cytoplasm and vesicular nuclei. These were probably the collecting tubules. Few tubules of smaller dimension lined by simple cuboidal cells with eosinophilic cytoplasm and rounded nuclei were seen, representing the thick segments of the loop of Henle. Some tubules lined by squamous epithelium and having small lumen appeared to be the thin segments of loop of Henle. The blood vessels lined by simple squamous epithelium with RBCs were seen.

At $16^{\text {th }}$ week, the mesenchymal connective tissue decreased in amount as compared to the previous stage. The collecting tubules possessed larger diameter and were lined by columnar cells while the thick segments of loop of Henle were lined by cuboidal cells. The thin segments of loop of Henle were lined by squamous epithelium and beared small lumen. More number of collecting tubules, thick and thin segments of loop of Henle were seen as compared to the previous stage.

At 20 weeks, the undifferentiated mesenchymal tissue further decreased in amount while the number of developing tubules increased. The collecting tubules, thick and thin segments of loop of Henle were better differentiated than the previous stage. In both the cortex and the medulla, vascularity of the kidney increased as compared to the previous stage.

At 24 weeks, the collecting tubules and thick and thin segments of loop of Henle were more in number. These were distinctly identified as 
compared to the previous stage.

At 36 weeks, the medulla showed well differentiated collecting tubules, thick and thin segments of loop of Henle.

These findings were compared with the findings of the following workers. After comparison, we found that the collecting tubules, thick and thin segments of loop of Henle were differentiated slightly earlier than that of the other workers. Our other findings of medulla were more or less comparable.

Mishra S et al [7] found that at 16 weeks of gestation, the medulla showed mesenchymatous tissue with some developing tubules. At 22 weeks of gestation, medulla seen to be much more mature. At 24 weeks, collecting ducts and loop of Henle appeared elongated.

Tank KC et al [8] observed that, at 12 weeks, the medulla contained undifferentiated mesenchymal tissue. At some places the cells were arranged in groups indicating the formation of collecting tubules. At 16 weeks, in medulla, the collecting tubules lined by columnar cells with clear cytoplasm and vesicular nuclei were seen. Few tubules with smaller dimension lined by simple cuboidal cells with eosinophilic cytoplasm and rounded nuclei were seen, identified as thick segments of the loop of Henle. At 17 weeks, both thick and thin segments were seen, lined by cuboidal and squamous epithelium respectively. At 24 weeks, medulla showed increased number of collecting tubules and thick and thin segments of loop of Henle with decreased amount of connective tissue. At 36 weeks, the medulla showed well differentiated collecting tubules, thick and thin segments of loop of Henle.

Syed SA et al [9] quoted that at 14 weeks, the medulla showed undifferentiated mesenchymal tissue with spindle shaped cells with pale cytoplasm and oval nuclei. At some places, the cells were arranged in groups indicating the formation of collecting tubules. The primitive blood vessels were lined by simple squamous epithelium, containing RBCs were seen. At 18 weeks, in medulla, irregular tubules of various dimensions were seen in between connective tissue. These might be the collecting tubules. Few tubules were lined by simple cuboidal cells with eosinophilic cytoplasm and rounded nuclei. These were probably thick segments of the loop of Henle. At 37-40 weeks, well differentiated collecting tubules, thick and thin segments of loop of Henle were seen in medulla.

Patil S at el [10] found that at 16 weeks, in medulla, few clusters of cells were seen along with connective tissue and primitive blood vessels. At 18 weeks, in medulla some of these tubules could be identified as collecting tubules and thick segments of loop of Henle. At 19-26 weeks, medulla showed increase in number of tubules and vascularity while decrease in connective tissue. The collecting tubule and thick loop of Henle were seen distinctly. At 29 weeks, medulla showed more number of collecting tubules and also the thick and thin segments of loop of Henle.

\section{CONCLUSION}

At 13 weeks, collecting tubules, thick and thin segments of loop of Henle were identified with abundant mesenchymal connective tissue with few blood vessels. They became well differentiated from 16 week onwards. Differentiation between cortex and medulla was seen from 16 week onwards. Vascularity of both cortex and medulla increased with increase in gestational age. Connective tissue of both cortex and medulla decreased with increase in gestational age. Renal pelvis lined by transitional epithelium was seen 16 week onwards. Most of the findings of the present study were in corroboration with the studies performed by the previous workers.

\section{Conflicts of Interests: None}

\section{REFERENCES}

[1]. Dyson M. Urinary System in Williams PL, Bannister LH, Berry MM, Collins P, editors. Gray's anatomy. 38th ed. Newyork, Edinburgh, London: Churchill Livingstone; 1995.

[2]. Moore KL, Persaud TVN. The developing human: Clinically oriented embryology. 8th ed. Philadelphia: Saunders Elsevier; 2008. p. 243-56.

[3]. Hamilton WJ, Boyd and Mossman. Human Embryology. 4th ed. The University of Michigan: Heffer Publication; 1972. p. 383-93.

[4]. Sadler TW, editor. Langman's medical embryology. 9th Ed. Baltimore: Lippincott Williams and Wilkins; 2006. p. 229-38. 
[5]. Healy JC. Urogenital system in Standring S, editor. Gray's anatomy: The Anatomical basis of Clinical Practice. $40^{\text {th }}$ ed. London: Churchill Livingstone Elsevier; 2008. p. 1225-1313.

[6]. Helena Maria Lizardo-Daudt et al. Diagnosis of the human age based on the development of normal kidney. Journal Brasileiro de patologia e medicina Laboratorial. 2002;38(2):1-10.

[7]. Mishra S, Dinesh A, Kaul JM. Morphological and morpho-metrical study of human renal development during mid gestational period. J Anat Soc India. 2006;55(2):5-10.
[8]. Tank KC, Saiyad SS, Pandya AM, Akbari VJ, Dangar KP. A study of histogenesis of human fetal kidney. Int J Biol Med Res. 2012;3(1):1315-21.

[9]. Syed SA, Joshi RA, Herekar NG. Histogenesis of Kidney in Human Fetuses. International Journal of Recent Trends in Science And Technology. 2012;3(2): 44-8.

[10]. Patil S, Patil P, Mane A. Histogenesis Of Human Fetal Kidney. NJIRM. 2012 Jul-Aug; 3(3): 122-27.

How to cite this article:

Rahul Kisan Ukey, Reshma Baburao Shinde, Anil Shivshankar Rahule, Prafulla Nikam, C.V. Diwan. HISTOGENESIS OF HUMAN FETAL RENAL MEDULLA. Int J Anat Res 2018;6(3.2):5544-5549. DOI: 10.16965/ijar.2018.277 